Original Article

\title{
Outcome Comparison of Endoscopic Third Ventriculostomy versus Ventriculoperitoneal Shunt in Obstructive Hydrocephalus
}

\author{
Ishfaque Ahmed Simair ${ }^{2}$, Hafiz Jawad Ali ${ }^{2}$, Amjad Qureshi ${ }^{3}$, Tarique Salah-ud-Din ${ }^{1}$ \\ ${ }^{1}$ Department of Neurosurgery, AMC/PGMI, PINS, Lahore General Hospital, Lahore, Pakistan. \\ ${ }^{2}$ Department of Neurosurgery, Lahore General Hospital, Lahore, Pakistan. \\ ${ }^{3}$ Department of Neurosurgery, Agha Khan University Hospital, Karachi, Pakistan.
}

\begin{abstract}
Background and Objectives: To assess the outcome of Endoscopic Third Ventriculostomy (ETV) versus Ventriculoperitoneal Shunt (VPS) in Obstructive Hydrocephalus in terms of infections, foreign bodies, costeffectiveness, and length of hospital stay.

Materials and Methods: It was a Randomized Controlled Trial study, in which 30 patients with Obstructive Hydrocephalus were divided into two groups one was treated with (ETV) and the other was treated with VP Shunt and the patients were followed up for 1 year.

Results: Patients were divided into 2 groups, 15 were treated with ETV, and 15 were treated with VP Shunt. Length of stay for VP shunt was $7 \pm 0.85$ days and for ETV mean stay was $2.93 \pm 1.1$ days. The complication was observed in 4 (26.7\%) treated with VP Shunt and in 3 (20\%) patients with Endoscopic Third Ventriculostomy. In ETV, 3 (20\%) patients had recurrence whereas in VP shunt in 1 (6.67\%) had an infection and in 3 (20\%) patients had recurrence (upper-end blockage) and the overall success rate was $76 \%$ in both the procedures and in VP Shunt $73.3 \%$ and ETV $80 \%$. Overall there were no complications found in 23 (76.6\%) patients, in $3(10 \%)$ patient's complications were found at $1^{\text {st }}$ month, in $3(10 \%)$ complications were observed at $3^{\text {rd }}$ month, and in $1(3.3 \%)$ complication was recorded at $6^{\text {th }}$ month.
\end{abstract}

Conclusion: ETV was found better in terms of length of hospital stay, cost-effectiveness as well as minimal complication rate as compared to VP shunt.

Keywords: Cerebrospinal Fluid, Endoscopic Third Ventriculostomy, Ventriculoperitoneal Shunt.

Abbreviations: ETV: Endoscopic Third Ventriculostomy. VPS: Ventriculoperitoneal Shunt. CSF: Cerebrospinal Fluid.

Corresponding Author: Ishfaque Ahmed Simair

Department of Neurosurgery

Lahore General Hospital, Lahore

Email: ishfaquesimair@gmail.com
Date of Submission: 10-06-2021

Date of Revision: 09-08-2021

Date of Acceptance: 15-09-2021

Date of Online Publishing: 30-09-2021

Date of Print: 30-09-2021

Dol: 10.36552/pjns.v25i3.583 


\section{INTRODUCTION}

Hydrocephalus is described as acute or chronic dilatation of all the ventricles either due to overproduction of Cerebrospinal Fluid (CSF) or a decrease in absorption. It is the most common disease in the pediatric population which needs immediate neurosurgery intervention. ${ }^{1}$ This might be the result of blocking the passage of CSF from the ventricles, restriction of CSF in subarachnoid areas around the brain; or insufficient absorption of CSF in the circulation from subarachnoid areas. Congenital abnormalities, infections (e.g. meningitis), cerebral hemorrhaging, and brain tumors comprise hydrocephalus causes. ${ }^{2}$ A modest increase in intracranial pressure is associated with hydrocephalus and brain abnormalities in some people, but high intracranial pressure does not affect the ventricles or brain functioning in others. ${ }^{3}$

Human hydrocephalus incidence follows a bimodal age curve. One peak occurs throughout childhood and is linked to certain congenital abnormalities. Another surge comes in adulthood, which is mostly due to NPH. Adult hydrocephalus accounts for around $40 \%$ of all hydrocephalus cases. Although much has been learned about the long-term and social effects of pediatric hydrocephalus, there is still much to learn. ${ }^{4}$

Hydrocephalus is prevalent in individuals with open neural tube defects (spina bifida cystica), but it has only been recorded in people with closed neural tube abnormalities (spina bifida occulta). Because of this uncommon but probable link, it is recommended that individuals with closed neural tube abnormalities be evaluated for clinical signs and symptoms of hydrocephalus. ${ }^{5}$

In one study patients with Acquired Hydrocephalus were assessed they showed they were associated with post-trauma sequelae. They represent $0.7 \%$ patients of with traumatic brain injury. Hydrocephalus was symptomatic within 1 year after trauma. Infections like meningitis, subarachnoid hemorrhage (SAH), tumors in the posterior fossa, intra-cerebral bleed, and surgery like craniotomy followed by trauma are the main factors that increased the incidence of posttraumatic hydrocephalus. VP shunt was passed in all patients, 8 patients improved markedly while 4 patients improved slowly. ${ }^{6}$

A Ventriculoperitoneal Shunt (VP shunt) is the most frequent procedure for hydrocephalus. Endoscopic third ventriculostomy (ETV) is an alternative surgical procedure. Infection, shunt obstruction, shunt catheter breakage, and other complications are common with shunts. ${ }^{7}$ They are susceptible to infection, especially in the first three months following surgery. Shunt infections can be fatal, and treatment is both costly and time-consuming. VP shunts are equally susceptible to failure. Within two years following initial shunt insertion, $40 \%$ of patients required a shunt revision, according to a new large prospective multi-institutional research. ${ }^{7}$

Endoscopic third ventriculostomy (ETV) is an alternate procedure for Obstructive Hydrocephalus. ${ }^{8}$ This treatment is non-invasive. It also prevents infection, shunt dependency, shunt malfunction, and the cost of a shunt. If hydrocephalus is caused by a blocking of CSF flow inside the ventricles, a blockage of the normal CSF outflow from the fourth ventricular, or a blockage to the CSF flow inside the basal subarachnoid areas around the fourth ventricle, the ETV will circumvent any of these blocks.

According to the literature, using ETV as the primary therapy in patients with hydrocephalus is safe and can result in a reduction of up to $21 \%$ in the shunted population of all newly diagnosed hydrocephalic patients. In individuals treated with ETV, complications are not related to their age. ${ }^{9}$ If done appropriately, endoscopic third ventriculostomy is a safe, straightforward, and successful therapeutic option for noncommunicating hydrocephalus. ${ }^{10}$ Endoscopy, as opposed to VP shunt, provides a good view of the operative site. As a result, a new study suggests that ETV be used as the primary treatment for obstructive hydrocephalus. ${ }^{11}$ 
The research was done to assess the longterm consequences of Endoscopic Third Ventriculostomy in patients who had previously had shunt insertion for obstructive hydrocephalus. A group of prospectively chosen patients was followed prospectively for at least 3 years. (Mean 63.6 months, range 36-103 months). Endoscopic Third Ventriculostomy is safe and effective for treating shunt malfunction in individuals with obstructive hydrocephalus; according to a one-year follow-up. ${ }^{7}$ 12-month follow-up research confirmed the same outcomes. $^{7}$

Infectious complications were discovered in 1.81 percent of patients. Meningitis (1.60 percent) and ventriculitis ( 0.21 percent) are among them; the prevalence of systemic infections was extremely low, and these infections are classified as systemic complications since they are caused by the patient's overall health and are unrelated to the treatment. CNS infections caused by ETV are usually successfully treated. However, in two of the patients in our study, the infection worsened to sepsis, which proved fatal for both individuals. In 1.61 percent of instances, there was a leak of cerebrospinal fluid. Sutures are used to cure this problem in most cases. ${ }^{12}$

Shunt infection is the commonest complication of VP shunt. Usually, it happens in $1^{\text {st }}$ month after VP Shunt insertion. Staphylococcus aureus is the most common pathogen responsible for shunt infection. If surgeons take proper sterilization precautions this infection rate can be decreased from $16 \%$ to $3 \% .^{13}$

\section{MATERIAL AND METHODS}

\section{Study Design and Setting}

After receiving clearance from the Ethical Committee, this Randomized Controlled Trial study was undertaken for one year at the Neurosurgery Department of Lahore General Hospital Lahore. In this study, 30 patients with Obstructive Hydrocephalus were separated into two groups, one receiving ETV and the other receiving VP Shunt, and the patients were followed up for a year. The sample size is computed using the method below, with the power of the research set to $95 \%$ and the threshold of significance set to $5 \%$. Each group should have a sample size of 15 people. The Shien-Chung Chow Formula was used to calculate sample size in clinical research). ${ }^{14}$

$$
n=\frac{\mathrm{z}_{\beta}^{2}\left[\mathrm{p}_{1}\left(1-\mathrm{p}_{1}\right)+\mathrm{p}_{2}\left(1-\mathrm{p}_{2}\right)\right]}{\left(p_{2}-p_{1}\right)^{2}}
$$

$P_{1}$ is the expected improvement proportions in the ETV Group $=76.90$ percent.

$\mathrm{P}_{2}$ represents the expected proportions of the VP Shunt Group, which is 50.0 percent.

The proportional difference between $p_{1}$ and $\mathrm{p}_{2}$ is 26.90 percent.

The targeted power of research $\left(Z_{2}\right)$ is 95 percent.

\section{Sampling Technique}

Non Probability, Purposive sampling. Treatment was assigned randomly using the random number tables for allocation of both the procedures accordingly to the patient.

\section{Inclusion Criteria}

All the patients with Obstructive Hydrocephalus either due to congenital or acquired (neoplastic), patients with ages between 16 to 60 years, and both male and female patients with no sex predilection were included in this study.

\section{Exclusion Criteria}

Previously operated patients with VP Shunt and those patients who have severe co-morbidities \& Infections were not included in this study.

\section{Data Analysis Procedure}

SPSS 23 was used to enter and analyze the data for this investigation. The numeric data, such as 
age and length of hospital stay, were input into Mean S forms. Deviation and qualitative data such as sex, CSF leaking, wound infection, and so forth was recorded as percentages and frequencies. The student t-test was used to assess the numeric data that matched the parametric assumption. The Chi-Square test was used to examine the qualitative data. When the $\mathrm{P}$-value was equal to or less than 0.05 , it was considered significant.

\section{RESULTS}

In this study 30 patients were studied, their mean age was $32.70 \pm 15.49$ years. Among them 20 (66.67\%) were female and 10 (33.33\%) were male as shown in (Table 1). Among these 30 patients, 15 were treated with Endoscopic Third Ventriculostomy and 15 were treated with VP Shunt.

Among Group A: VP shunt treated patients the age was $31.13 \pm 16.28$ years and among ETV group B $34.27 \pm 15.06$ years. Length of stay for VP shunt was $7 \pm 0.85$ days and for ETV mean stay was $2.93 \pm 1.10$ days.

Table 1: Comparison of Gender among Treatments.

\begin{tabular}{lccc|} 
& \multicolumn{2}{c}{ Gender } & Total \\
Group A: VP Shunt & $9(60 \%)$ & $6(40 \%)$ & 15 \\
Group B: ETV & $11(73.3 \%)$ & $4(26.7 \%)$ & 15 \\
Total & $20(66.7 \%)$ & $10(33.3 \%)$ & 30 \\
\hline
\end{tabular}

Chi square test $0.60 \mathrm{p}$-value 0.70

Note: No gender difference was made in the allotment of treatment.

Overall there were no complications found in 23 (76.6\%) patients, in 3 (10\%) complications were found at $1^{\text {st }}$ month, in $3(10 \%)$ complications were recorded at $3^{\text {rd }}$ month and in 1 (3.3\%) it was recorded at $6^{\text {th }}$ month as shown in (Table 2). No complications were noted at the end of the study (i.e. at $12^{\text {th }}$ month). In Group B (ETV) total of 15 patients were followed and out of the 3 (20\%)
Table 2: Comparison of Complications among Treatments.

\begin{tabular}{lcccccc|}
\multicolumn{7}{c}{ Complication } \\
Months & $\begin{array}{c}\text { No } \\
\text { Complication }\end{array}$ & $\mathbf{1}$ & $\mathbf{3}$ & $\mathbf{6}$ & $\mathbf{1 2}$ & Total \\
$\begin{array}{l}\text { Group } \\
\text { A: VP }\end{array}$ & $11(73.3 \%)$ & 1 & 2 & 1 & 0 & 15 \\
Shunt & & $(6.7 \%)$ & $(13.3 \%)$ & $(6.7 \%)$ & & \\
$\begin{array}{l}\text { Group B: } \\
\text { ETV }\end{array}$ & $12(80 \%)$ & 2 & 1 & 0 & 0 & 15 \\
Total & $23(16.6 \%)$ & $3(10 \%)$ & $3(10 \%)$ & 1 & 0 & 30 \\
\hline
\end{tabular}

Chi square test 1.710, p-value $>0.05$

patients have complications in the form of recurrence. Twelve (80\%) patients had no complication whereas in Group A (VP shunt) total of 15 patients were followed and 4 (26.7\%) patients had complications and out of the 1 (6.67\%) patient had an infection and 3 (20\%) patients had a recurrence and 11 (73.3\%) had no complications. Length of stay for VP shunt was 7 \pm 0.85 days and for ETV mean stay were $2.93 \pm$ 1.1 days as shown in (Table 3 ).

Table 3: Comparison of Length of Stay at Hospital among Treatments.

\begin{tabular}{lcccc} 
Group & N & Mean & $\begin{array}{c}\text { Standard } \\
\text { Deviation }\end{array}$ & $\begin{array}{c}\text { Standard } \\
\text { Error Mean }\end{array}$ \\
$\begin{array}{l}\text { Group A: } \\
\text { VP Shunt }\end{array}$ & 15 & 7 & 0.845 & 0.218 \\
$\begin{array}{l}\text { Group B: } \\
\text { ETV }\end{array}$ & 15 & 2.93 & 1.1 & 0.284 \\
\hline
\end{tabular}

T-test $11.3 p$-value $<0.001$

The average cost of each patient treated with ETV was around 17000 rupees as the patient was admitted for an average of 3 days and it was 52000 rupees for the patients treated with VP shunt as the patient was admitted for an average of 7 days. The ratio between these two is $1: 3$ which indicates that ETV is a much better choice than VP shunt in terms of cost-effectiveness as shown in (Table 4). 


\begin{tabular}{|c|c|c|}
\hline Cost & Group B - ETV & Group A - VP Shunt \\
\hline CT scan & 3000 & 3000 \\
\hline Labs & 2000 & 2000 \\
\hline \multirow{2}{*}{ Medicine } & 3000/day & 3000/day \\
\hline & For 3 days $=9000$ & For 7 days $=21000$ \\
\hline OT Medicines & 3000 & 3000 \\
\hline VP Shunt & & 23000 \\
\hline Grand Total & 17000 & 52000 \\
\hline
\end{tabular}

Note: These values are for one patient in Pakistani Rupees

\section{DISCUSSION}

The management of Obstructive Hydrocephalus has been a matter of debate for decades. Either to go for VP Shunt, which has been a workhorse method for a neurosurgeon, or too apt for a contemporary method of treatment i.e., endoscopic third ventriculostomy (ETV). VP Shunt is a lifelong foreign body that carries risks for shunt blockage and shunts infection while ETV is a new modality that has decreased the rate of complications. In this study, these complications have been rationalized to decreases the morbidity rate.

In one study ETV and VP shunts were compared in those patients who were having obstructive Hydrocephalus. Both procedures were effective post-operatively but had few complications like CSF leak, bleeding, and shunt infection. Even subdural and extradural hematomas are infrequent in patients. The decreased morbidity rate and insignificant fatality rate are due to the shorter time of operation. Endoscopic Third Ventriculostomy (ETV) is one of the most effective treatment options for obstructive hydrocephalus patients. ${ }^{7}$

Previous shunt-associated infection, shunt revision for malfunction, postoperative CSF leakage, advanced age, duration of the shunt insertion procedure, and neurosurgeon expertise have all been found as independent risk factors. ${ }^{15}$ In a recent study in which advanced statistical analysis was used, it showed that the Endoscopic Third Ventriculostomy has a lower rate of failure than VP shunt in the immediate postoperative phase and as time pass it has more success rate than $\mathrm{V} P$ shunt and became even more favorable with a longer duration from surgery.

Infection of the cerebrospinal fluid (CSF) shunt is a leading cause of morbidity and death in the treatment of hydrocephalus, as well as a large financial burden. ${ }^{7}$ Within one year of the initial shunt implantation, 496 (3.9\%) individuals were found who had a shunt infection and were treated for it. Time to shunt infection was 4.6 [4.1-13.3] weeks on average [inter-quartile range]. The overall cost of shunt infection treatment was $\$ 23,879,424 \quad(\$ 48,144 \$ 54,021$ per shunt infection). ${ }^{16}$ In full-term neonates' VP shunt procedures reviled a high prevalence of Hydrocephalus. ${ }^{5}$ In comparison to endoscopic third ventriculostomy (ETV), shunts are often linked with a reduced post-treatment ventricular size, however, review studies to date confirm ETV as an efficient surgical procedure for hydrocephalic individuals. ${ }^{17}$

In our study, the overall success rate was $76 \%$, whereas in ETV the success rate was about $80 \%$ which is higher than the reported success rate. In a long-term follow-up study, the success rate was $71.3 \% 18$. Similar to the literature in our study the ETV was better than the VP shunt. ${ }^{19}$ According to a recent study; ETV has a broad use in adult hydrocephalus, with a low complication rate and reasonable effectiveness in chosen patients. ${ }^{7}$

In our study total, 30 patients were followed for 1 year and they have divided into 2 groups and each group had 15 patients, in Group A (VP shunt) total of 15 patients were followed and 4 (26.7\%) patients had complications and out of the $1(6.67 \%)$ patient had an infection and 3 (20\%) patients had a recurrence and 11 (73.3\%) had no complications. Whereas in Group B (ETV) total of 15 patients were followed and out of the $3(20 \%)$ patients had complications in the form of recurrence. Twelve (80\%) patients had no complications. Overall there were no complications found in 23 (76.6\%) patients, in 3 
(10\%) complications were found at $1^{\text {st }}$ month, in 3 (10\%) complications were recorded at $3^{\text {rd }}$ month and $1(3.3 \%)$ complication was recorded at $6^{\text {th }}$ month. No complications were noted at the end of the study (12 $2^{\text {th }}$ month).

The average cost of each patient treated with ETV was around 17000 rupees as the patient was admitted for an average of 3 days and it was 52000 rupees for the patients treated with VP shunt as the patient was admitted for an average of 7 days. The ratio between these two is $1: 3$ which indicates that ETV is a much better choice than VP shunt in terms of cost-effectiveness. It could be easily determined from the literature that in terms of post-operative success rate and morbidity, infection, cost-effectiveness and length of hospital stay in Endoscopic third ventriculostomy is better than conventionally used treatment ventriculoperitoneal shunt (VPS).

\section{CONCLUSION}

In comparison to the VP shunt, Endoscopic Third Ventriculostomy (ETV) was proven to be better in terms of infection, length of hospital stay, costeffectiveness, and complication rate.

\section{REFERENCES}

1. Joó JG, Tóth Z, Beke A, Papp C, Tóth-Pál E, Csaba $A_{\text {, }}$ et al. Etiology, prenatal diagnostics and outcome of ventriculomegaly in 230 cases. Fetal Diagnosis and Therapy, 2008;24 (3): 254-63.

2. Kamalo P. Exit ventriculoperitoneal shunt; enter endoscopic third ventriculostomy (ETV): contemporary views on hydrocephalus and their implications on management. Malawi medical journal: the journal of Medical Association of Malawi. 2013; 25 (3): 78-82.

3. Hakim S, Venegas JG, Burton JD. The physics of the cranial cavity, hydrocephalus and normal pressure hydrocephalus: mechanical interpretation and mathematical model. Surg Neurol. 1976; 5 (3): 187210.

4. Kinsman SL, Johnston MV. Congenital anomalies of the central nervous system. Nelson Textbook of
Pediatrics 18th ed Philadelphia, Pa: Saunders Elsevier, 2007: 592.

5. Chance A, Sandberg DI. Hydrocephalus in patients with closed neural tube defects. Child's Nervous System, 2014; 31 (2): 329-32.

6. Cardoso ER, Galbraith S. Posttraumatic hydrocephalus-A retrospective review. Surg Neurol. 1985; 23 (3): 261-4.

7. Alkhafaji A, Hassan SF. A comparative study between ventriculoperitoneal shunt and endoscopic third ventriculostomy in the management of obstructive hydrocephalus. Iraqi Postgrad Med J. 2014; 13 (4): 486-92.

8. Zandian A, Haffner $M$, Johnson J, Rozzelle CJ, Tubbs RS, Loukas M. Endoscopic third ventriculostomy with/without choroid plexus cauterization for hydrocephalus due to hemorrhage, infection, Dandy-Walker malformation, and neural tube defect: a metaanalysis. Child's nervous system: ChNS: official journal of the International Society for Pediatric Neurosurgery, 2014; 30 (4): 571-8.

9. Javadpour M, Mallucci C, Brodbelt A, Golash A, May P. The Impact of Endoscopic Third Ventriculostomy on the Management of Newly Diagnosed Hydrocephalus in Infants. Pediatric Neurosurgery, 2001; 35 (3): 131-5.

10. Schroeder HW, Niendorf W-R, Gaab MR. Complications of endoscopic third ventriculostomy. Journal of Neurosurgery, 2002; 96 (6): 1032-40.

11. Eguchi S, Aihara Y, Tsuzuki S, Omura Y, Kawamata T, Okada Y. A modified method to enhance the safety of endoscopic third ventriculostomy (ETV) transendoscopic pulse-waved microvascular Doppler-assisted ETV, technical note. Child's Nervous System, 2014; 30 (3): 515-9.

12. Bouras T, Sgouros S. Complications of endoscopic third ventriculostomy. Journal of Neurosurgery: Pediatrics, 2011; 7 (6): 643-9.

13. Rehman A-u, Rehman T-u, Bashir HH, Gupta V. A simple method to reduce infection of ventriculoperitoneal shunts. Journal of Neurosurgery: Pediatrics, 2010; 5 (6): 569-72.

14. Chow S-C, Chang $M$, Pong A. Statistical Consideration of Adaptive Methods in Clinical Development. Journal of Biopharmaceutical Statistics, 2005; 15: 575-91. 
15. Conen A, Walti LN, Merlo A, Fluckiger U, Battegay M, Trampuz A. Characteristics and Treatment Outcome of Cerebrospinal Fluid Shunt-Associated Infections in Adults: A Retrospective Analysis over an 11-Year Period. Clinical Infectious Diseases, 2008; 47 (1): 73-82.

16. Parker SL, McGirt MJ, Murphy JA, Megerian JT, Stout M, Engelhart L. Cost Savings Associated with Antibiotic-Impregnated Shunt Catheters in the Treatment of Adult and Pediatric Hydrocephalus. World Neurosurgery, 2015; 83 (3): 382-6.

17. Azab WA, Mijalcic RM, Nakhi SB, Mohammad MH. Ventricular volume and neurocognitive outcome after endoscopic third ventriculostomy: is shunting a better option? A review. Child's Nervous System, 2016; 32 (5): 775-80.

18. Grunert P, Charalampaki P, Hopf N, Filippi R. The role of third ventriculostomy in the management of obstructive hydrocephalus. Minim Invasive Neurosurg. 2003; 46 (1): 16-21.

19. Isaacs A, Urbaneja G, Hamilton M. Endoscopic third ventriculostomy (ETV) for treatment of adult hydrocephalus: long-term followup with 163 patients. Fluids and Barriers of the CNS. 2015; 12 (1): 1 -.

\section{Additional Information}

Disclosures: Authors report no conflict of interest.

Ethical Review Board Approval: The study was conformed to the ethical review board requirements.

Human Subjects: Consent was obtained by all patients/participants in this study.

\section{Conflicts of Interest:}

In compliance with the ICMJE uniform disclosure form, all authors declare the following:

Financial Relationships: All authors have declared that they have no financial relationships at present or within the previous three years with any organizations that might have an interest in the submitted work.

Other Relationships: All authors have declared that there are no other relationships or activities that could appear to have influenced the submitted work.

\section{AUTHORS CONTRIBUTIONS}

\begin{tabular}{|l|l|l|}
\hline Sr.\# & Author's Full Name & Intellectual Contribution to Paper in Terms of: \\
\hline 1. & Tariq Salah ud Din & 1. $\quad$ Study design and methodology. \\
\hline 2. & Ishfaque Ahmed Simair & 2. $\quad$ Paper writing and data calculations. \\
\hline 3. & Hafiz Jawad Ali & 3. $\quad$ Data collection and calculations. \\
\hline 4. & Amjad Qureshi & 4. $\quad$ Analysis of data and interpretation of results etc. \\
\hline
\end{tabular}

